Groenewegen, P.P., Dourgnon, P., Greß, S., Jurgutis, A., Willems, S. Strengthening weak primary care systems: steps towards stronger primary care in selected Western and Easter European countries. Health Policy: 2013, 113(1), 170-179

\begin{tabular}{l|l}
$\begin{array}{l}\text { Postprint } \\
\text { Version }\end{array}$ & 1.0 \\
Journal website & http://www.healthpolicyirnl.com/article/S0168-8510(13)00164-4/abstract \\
\hline Pubmed link & $\underline{\text { http://www.ncbi.nlm.nih.gov/pubmed/23895880 }}$ \\
\hline DOI & 10.1016/j.healthpol.2013.05.024
\end{tabular}

This is a NIVEL certified Post Print, more info at http://www.nivel.eu

\title{
Strengthening weak primary care systems: Steps towards stronger primary care in selected Western and Eastern European countries *
}

\author{
Peter P. GroeneWegen ${ }^{\mathrm{A}, \star}$, PAul DourgnoN ${ }^{\mathrm{B}, 1}$, Stefan Greß ${ }^{\mathrm{C}, 2}$, ArNoldas Jurgutis ${ }^{\mathrm{D}, 3}$, \\ SARA WILLEMS ${ }^{\mathrm{E}, 4}$ \\ ${ }^{a}$ NIVEL - Netherlands Institute for Health Services Research and Utrecht University, Dep. of \\ Sociology and Dep. of Human Geography, NIVEL, PO Box 1568, 3500 BN Utrecht, The \\ Netherlands \\ ${ }^{\mathrm{b}} 10$ rue Vauvenargues, 75018 Paris, France \\ c University of Applied Sciences Fulda, Dep. of Nursing and Health Sciences, \\ Marquardstrasse 35, D - 36039 Fulda, Germany d Klaip eda University, Herkaus Manto \\ str. 84, LT - 92294, Klaipeda, Lithuania e Ghent University, Department of Family Medicine \\ and Primary Health Care, 6K3 - De Pintelaan 185, 9000 Gent, Belgium
}

\begin{abstract}
A B S T R A C T
European health care systems are facing diverse challenges. In health policy, strong primary care is seen as key to deal with these challenges. European countries differ in how strong their primary care systems are. Two groups of traditionally weak primary care systems are distinguished. First a number of social health insurance systems in Western Europe. In these systems we identified policies to strengthen primary care by small steps, characterized by weak incentives and a voluntary basis for primary care providers and patients. Secondly, transitional countries in Central and Eastern Europe (CCEE) that transformed their staterun, polyclinic based systems to general practice based systems to a varying extent. In this policy review article we describe the policies to strengthen primary care. For Western Europe, Germany, Belgium and France are described. The CCEE transformed their systems in a completely different context and urgency of problems. For this group, we describe the situation in Estonia and Lithuania, as former states of the Soviet Union that are now members of the EU, and Belarus which is not. We discuss the usefulness of voluntary approaches in the context of acceptability of such policies and in the context of (absence of) European policies.
\end{abstract}


Groenewegen, P.P., Dourgnon, P., Greß, S., Jurgutis, A., Willems, S. Strengthening weak primary care systems: steps towards stronger primary care in selected Western and Easter European countries. Health Policy: 2013, 113(1), 170-179

\section{INTRODUCTION}

Strong primary care is often seen as a solution for the challenges that (European) health care systems face [1] and [2]. This raises the policy question of how primary care systems can be strengthened and especially those primary care systems that are traditionally weak. This question will be answered in this article by reviewing changes in two broad groups of health care systems with relatively weak primary care that introduced changes towards a stronger position of primary care. The first group consists of Western European social health insurance systems; the second group consists of transitional countries in Central and Eastern Europe (CCEE) that (partly) moved from a state-run, polyclinic system to a primary care based system.

Primary care is 'generalist care, consisting of general medical, (physio)therapeutical and pharmaceutical care, nursing and supportive care, and non-specialized mental and social care, together with preventive and health educational activities linked to these forms of care' [3]. Primary care provides in most cases the first point of contact with health care. Strong primary care can be characterized by its generalist approach, taking into account the social and family context of patients, by its accessibility, and by providing continuity, comprehensiveness and coordination of care [4], [5] and [6]. Typical for strong primary care are a list system, i.e. a defined population for which primary care or general practice is responsible, and a position of general practitioners (GPs) as gatekeepers.

Several positive effects of strong primary care have been documented in the literature [6]: better health outcomes [7], good quality care [8], lower costs [9], and better opportunities for cost containment [10]. Moreover, strong primary care systems provide better opportunities for monitoring health, health care utilization and quality, partly because of the defined population denominator in systems with patient lists [3]. However, the evidence from international comparative studies is not unequivocally strong and mixed in some areas, such as health care expenditures [11], weak in other areas, such as equity [6] and [12] and avoidable hospitalizations [13], and finally negative in areas related to cancer survival [14].

European health care systems face a number of challenges related to changes on the demand side of care. Health care needs are increasing and changing as a consequence of demographic and socio-cultural changes. People live longer, although not necessarily in good health [15]. They want (or need) to stay longer in their own homes. Many elderly have multiple and complex health problems [16] and [17]. People are better educated and more demanding as patients and there is increasing diversity in cultural background of patients as a result of complex and multiple migration flows. These socio-cultural changes ask for more patient-centred care. There are also still large and increasing inequalities in health and in access to healthcare [18], [19] and [20].

To meet these challenges, the World Health Report 2008 [1] has called for stronger primary care. Currently, primary care is often provided in single-handed GP practices with few opportunities for teamwork; incentives both on the supply side and the patient side often do not support strong primary care; different primary care providers are separately funded from different sources, hampering cooperation; payment systems favour separate services instead of integrated care; patients often do not have incentives to visit the same primary care providers and information on patients' illness history and health care utilization is scattered and not available at one 
Groenewegen, P.P., Dourgnon, P., Greß, S., Jurgutis, A., Willems, S. Strengthening weak primary care systems: steps towards stronger primary care in selected Western and Easter European countries. Health Policy: 2013, 113(1), 170-179

point. The sustainability of health care systems is threatened by the unbalanced growth of specialist care, with shifts from hospital to primary care difficult to realize without profound changes in primary care. Finally, demographic changes also result in a projected lack of qualified manpower in health care [21] and [22]. Among European countries with traditionally weak primary care systems a first group of social health insurance or Bismarckian systems in Western Europe, such as in Belgium, France and Germany, stand out. They are characterized by the small scale organization of primary care in predominantly single-handed practices, by a strong emphasis on freedom of choice, and by demand channelling via co-payments (as compared to gate keeping systems [23]). In these countries we see policy changes to strengthen primary care based on weak incentives and a voluntary basis: GP models in Germany, medical file keeping in Belgium, and preferred GPs in France. A second group of European health care systems with relatively weak primary care are the health care systems in CEE after the transition from communism. Those who joined the European Union (EU) felt a strong urge to reform their health care systems, both from internal (lack of efficiency, worsening health outcomes) and external pressures (accession rules of the EU) [24]. Their strategy was to introduce major reforms, including stronger restrictions such as the introduction of gatekeeping. However, those who did not join the EU had a much slower reform process and still have many characteristics of the Semashko health care system.

In this article we aim to describe these two groups of countries and the way in which they have attempted to change their weak primary care systems to strengthen primary care. The question we will answer is: How have countries with a weak primary care system attempted to strengthen their primary care system?

\section{MeTHODOLOGICAL APPROACH}

The research reported in this article is a policy review and the approach can be characterized as comparative descriptive. The description of the policy initiatives and changes is based on published literature (both national and international) and documents describing the policy changes and their backgrounds.

\subsection{Selection of countries}

We were interested in policies to strengthen primary care in European countries. As a starting point we have looked for countries with a weak primary care system [25]. In CEE the legacy of communism with its Semashko health care systems was one of weak primary care systems [25] and [26]. From these countries we selected three examples that used to be part of Soviet Union and two of which entered the EU -

Estonia and Lithuania - and one that did not - Belarus. In Western Europe we have selected three countries with a relatively weak primary care system, as indicated by the absence of gate keeping and several dimensions of strong primary care [27]. The countries selected are Germany, Belgium and France.

\subsection{Dimensions of descriptive analysis}

Our analysis focuses on the common elements in the primary care related policies in each of the two groups of countries, on the incentives that were used, and the availability of evidence for the success of the policies. 
Groenewegen, P.P., Dourgnon, P., Greß, S., Jurgutis, A., Willems, S. Strengthening weak primary care systems: steps towards stronger primary care in selected Western and Easte European countries. Health Policy: 2013, 113(1), 170-179

\section{WESTERN EUROPE}

Western European health care systems vary in how strong their primary care systems are. Macinko et al. [7] have characterized OECD countries on the basis of a composite index for primary care strength that takes into account national policies, health care funding, generalists as predominant primary care providers, cost sharing for primary care, patients lists and gate-keeping. In their classification, the weak primary care systems in Western Europe were mainly social health insurance (Bismarckian) systems. Although there are large differences between these systems, many are characterized by an absence of a list system or gatekeeping. Traditionally these systems have a strong emphasis on freedom of choice, both of health care providers (the 'liberal professions') and of patients (freedom to visit the physician of their choice, be it in primary or secondary care). If there are restrictions on demand at all, demand is channelled via co-payments. The organizational scale is small with a large share of single-handed GP practices with few support staff and little cooperation with other health care professions.

Against this background Box 1, Box 2 and Box 3 describe three cases of policy changes towards stronger primary care: the GP models in Germany, the system of preferred GP in France and the centralized medical record in Belgium. All three cases have in common that they tie patients to a specific GP or practice on voluntary basis. In the French system this is not necessarily a GP, but in practice $99 \%$ or more are GPs. In the Belgian model medical record keeping is the central mechanism, as was meant to be part of the French system too. In all three cases the system operates via incentives for patients (lower co-payments for GP care and higher reimbursement of costs of specialist care when referred) and for GPs (fixed fees per patient who registers in Germany and Belgium and certain categories of patients in France). The coverage of the systems vary: approximately $20 \%$ in Germany, close to $50 \%$ in Belgium and 80\% in France (see Box 1, Box 2 and Box 3). Research on the effects of the policies is scarce and what evidence there is, shows small effects.

\section{[вох 1] [Bох 2][вох 3]}

\section{CENTRAL AND EASTERn EUROPE}

The CCEE emerged from the fall of communism with health care systems that were modelled after the Soviet Union's system. They were not primary care oriented. The point of departure was state funded systems with parallel provision of care for specific groups of the population, such as the military or the employees of large companies. Health care providers in ambulatory care were salaried employees of (usually) large specialist centred polyclinics organized on a geographic basis. The government had a strong role and health care was an integral but low priority part of the command and control economy [40]. Hospitals were the leading health care institutions in geographic and administrative units. The head of the hospital was responsible for planning and distribution of resources for all subordinate institutions, including polyclinics, located in cities, and rural ambulatories (small out-patient units) in rural areas. The lowest level in this strongly hierarchical system were district internists, responsible for the adult population, and district paediatricians, responsible for children, in a defined geographic area. These district doctors were trained as specialists in internal medicine or paediatrics mainly in university 
Groenewegen, P.P., Dourgnon, P., Greß, S., Jurgutis, A., Willems, S. Strengthening weak primary care systems: steps towards stronger primary care in selected Western and Easter European countries. Health Policy: 2013, 113(1), 170-179

hospitals. Family medicine, as a discipline, used to be recognized only in Yugoslavia [26]. There was no patient choice of provider [41].

The CCEE that became members of the EU have introduced some form of social health insurance [24] and [42]. In many countries primary care was the starting point for reforms [43]. Against the background of these reforms towards more primary care, Box 4, Box 5 and Box 6 describe three examples from former Soviet Union countries, the Baltic countries Lithuania and Estonia that are now members of the EU, and Belarus.

\section{[Box 4][воX 5][вох 6]}

Of the countries that emerged from the former Soviet Union the most intensive reforms have been implemented in the Baltic countries. Directly after independence the parliaments of Estonia and Lithuania have adopted health reform strategies that emphasized on primary health care and introduction of family medicine (the Estonian National Development Programme and the Lithuanian National Health Concept both of 1991). Part of the primary care oriented reforms was the introduction of gatekeeping and remuneration of GPs based on capitation. In Estonia this was extended with quality related bonus which is currently being discussed in Lithuania too, because of negative consequences of flat capitation for the uptake of preventive services and access in rural areas. A major challenge for Estonia and Lithuania was to train GPs and retrain district internists/therapists and district paediatricians to take up a new role in decentralized and often privatized primary care.

Belarus, and the former Soviet Union countries that did not become members of the EU in general, have adopted more conservative policies in changing their former health care system [44]. The Belarus health care system is still state funded, with smaller steps towards stronger primary care. Belarus has a dual system with polyclinics in the cities and GP based primary care in rural areas, and no gate keeping. Lithuania also has polyclinics in the biggest cities, which probably paves the way for private practices also to accommodate specialist services within their organization.

There is evidence from Lithuania that service provision patterns of retrained district therapists and paediatricians have changed since the early 1990s, showing a stronger role as doctors of first contact and more involvement in chronic disease management [45]. Moreover, GPs better address the health needs of families and people are more satisfied with their GPs than with district doctors [46] and [47].

\section{DISCUSSION}

There are important differences in the policy developments of the health care systems with weak primary care in the west and east of Europe, described in this policy review article. The Western European countries with a relatively weak primary care system that we discussed have developed policies with incentives for patients and providers and a voluntary character. The CCEE that joined the EU had to reform their health care systems much more drastically and have opted for strengthening primary care by introducing GPs with a gate-keeping function. For the Western European approach to introduce gatekeeping the term 'soft gatekeeping' has been used [61]. However, although the gatekeeping in the CCEE that joined the EU 
Groenewegen, P.P., Dourgnon, P., Greß, S., Jurgutis, A., Willems, S. Strengthening weak primary care systems: steps towards stronger primary care in selected Western and Easter European countries. Health Policy: 2013, 113(1), 170-179

is quite strong on paper, in day-to-day practice it seems much 'softer'. Gatekeeping is sometimes partial and there are discrepancies between the rules and actual practice [62].

To understand the differences in policy development we should be aware that the context of the reforms differs strongly. A first difference is in the urgency of reforms. The CCEE had to transform their health care systems after the fall of communism. Public health indicators were quickly worsening and there was widespread dissatisfaction with the Semashko system. The economic reform programmes also involved the health care sector. The reforms in Western European countries towards stronger primary care miss this urgency, despite the rhetoric of ageing populations, increasing complexity of health problems and expected human resource shortages. Probably the current economic crisis with its pressure on health care budgets changes this [63]. The primary reaction, however, seems to be to contain costs by increasing budgetary pressures on health care providers or increase co-payments for patients (or both). A second and related difference is the affordability of health care spending. At the time that CCEE started to reform their health care systems they were not in a position to risk a large increase in spending. All in all, there is an increasing need to rationalize service delivery in a context of huge financial pressure due to the global crisis and rising structural sustainability concerns, linked to the rise in treatment costs and chronic diseases prevalence and mal-distribution of health professionals.

A third difference is that the Western European countries that we described in this article are all long established social health insurance systems, while the countries in the east that became members of the EU transformed their systems from centrally led budget funding to social health insurance systems. In general it is easier to change systems that have a strong role of the state than systems where power is divided between the state, health care providers and insurance organizations [64] and [65]. We can illustrate this by looking at the role of (ambulatory) specialists. In the social health insurance systems in Western Europe the position of medical specialists is both stronger than that of GPs and they have an interest in free access of patients to specialist care. This is clearest in the case of France where some specialties are freely accessible, even for patients who participate in the preferred GP scheme, and where some specialties were compensated for loss of income. Although it can be argued that hospital specialists had a stronger position than district doctors in the former communist countries, the reforms changed this. Retrained district doctors and GPs were able to start private practices and the hospital sector was under pressure. Consequently, there seems to have been less opposition from medical specialists to a stronger position of primary care.

Finally, there are important large differences in values and expectations of patients in Western Europe and CCEE. The former communist countries had a past experience of low patient choice, while the Western European countries that we discussed are characterized by a strong culture of choice, both on the patient and on the provider side. This probably partly explains the resistance to stronger incentives for gatekeeping [31] and [66].

All in all this makes the choice of policies based on weak incentives and voluntarism in the west and much stronger policies in the east understandable.

An important question is whether or not the policy of weak incentives and voluntary approaches is strong enough to result in a health care system that is able to address the challenges of today and of the following decades. Yet, this policy might be seen 
Groenewegen, P.P., Dourgnon, P., Greß, S., Jurgutis, A., Willems, S. Strengthening weak primary care systems: steps towards stronger primary care in selected Western and Easter European countries. Health Policy: 2013, 113(1), 170-179

as a first step with stronger incentives and more restrictive policies to follow. Strong primary care is not something that develops naturally without focused policy-making [67]. There is no EU policy in this area, although implicitly, the accession rules might have influenced the course of health care reforms in the CCEE. In general EU policies (freedom of movement, competition) tend to favour increasing freedom of choice rather than restriction of choices.

The policies of weak incentives in Western European countries are not isolated. In most Western European health care systems forms of disease management are being introduced [68]. The capitation payment in the French referring GP system is restricted to chronic patients that participate in the scheme. In Germany and Belgium disease management programmes are introduced apart from the GP model and the centralized medical record scheme respectively. Integration of different policies that aim at stronger primary care could strengthen these policies. Also the emphasis in current policies on the performance of health care providers, such as in pay-forperformance schemes, might influence policies to strengthen primary care. Some form of a defined patient list or geographical boundaries is a necessary condition for performance payment and it has been suggested that this is at the background of the French reforms [34]. At the same time these are key conditions for strengthening primary care in weak primary care systems.

The reforms in the CCEE were not only positive. The privatization of primary care in the CCEE that now are part of the EU resulted in a scale of general practices which is much smaller than the previous polyclinics [43]. This might have consequences for further development of primary care in these countries. Although size of the organization does not automatically implicate a relationship with quality and average quality (measured by indicators from the Quality and Outcomes Framework) is comparable, there is more variation in smaller practices [69]. Patients are often more satisfied with smaller practices, while formal quality system related indicators are usually better in larger practices. In general patient satisfaction is higher in social health insurance systems, probably partly because of the greater choice of provider in the absence of gate keeping [70] and [71].

\section{CONCLUSION}

There are many different policy initiatives in Europe aiming to strengthen primary care. The contents of these policies differ according to the history and context of health care systems. Here we have reviewed some of these contexts. However, we are not able to answer the question how in general stronger primary care can be reached. In our view it is important to use the variation in contexts and policies in Europe to systematically analyze how stronger primary care is reached. Current reforms should be evaluated to find an answer to the question whether or not weak incentives for patients and GPs can set off a transformation process [49], [72] and

[73]. As patients' preferences and experiences become increasingly important in the evaluation of health care, it is important to know more about the acceptability of policies that leave room for individual choice. For this and related questions, e.g. on health outcomes and equity, Europe is our research laboratory [74]. 
Groenewegen, P.P., Dourgnon, P., Greß, S., Jurgutis, A., Willems, S. Strengthening weak primary care systems: steps towards stronger primary care in selected Western and Easter European countries. Health Policy: 2013, 113(1), 170-179

\section{REFERENCES}

[1] WHO. World Health Report 2008: Primary Care Now More than Ever.Geneva: WHO; 2008.

[2] Starfield B. Toward international primary care reform. CanadianMedical Association Journal 2009;180(11):1091-2.

[3] Health Council of the Netherlands. European Primary Care. TheHague: Health Council; 2004.

[4] Starfield B. Is primary care essential? Lancet 1994;344:1129-33.

[5] Boerma W, Fleming D. The Role of General Practice in Primary Care.Europe: World Health Organization; 1998.

[6] Kringos DS, Boerma WGW, Hutchinson A, Van der Zee J, Groenewe-gen PP. The breath of primary care: a systematic literature review ofits core dimensions. BMC Health Services Research 2010;10:65.

[7] Macinko J, Starfield B, Shi L. The contribution of primary care sys-tems to health outcomes within OECD countries, 1970-1997. HealthServices Research 2003;38:831-65.

[8] Groenewegen PP, Delnoij DMJ. Wat zou Nederland zijn zonder dehuisarts? Utrecht: Elsevier/De Tijdstroom; 1997.

[9] Gerdtham U, Jønsson B. Factors affecting health spending: a cross-country econometric analysis. In: OECD, editor. New Directions inHealth Care Policy: Health Policy Studies No. 7. Paris: OECD; 1995. p.71-89.

[10] Delnoij DMJ, van Merode G, Paulus A, Groenewegen PP. Does generalpractitioner gatekeeping curb health care expenditure? Journal ofHealth Services Research and Policy 2000;5:22-6.

[11] Kringos DS, Boerma WGW, Van der Zee J, Groenewegen PP. Europe'sstrong primary care systems are linked to better population health,but also to higher health spending. Health Affairs 2013;32:686-94.

[12] Or Z, Jusot F, Yilmaz E. Impact of Health Care System on Socioeco-nomic Inequalities in Doctor Use. Paris: Irdes; 2008, working paper.

[13] Purdy S. Avoiding Hospital Admissions: What Does the Research Evi-dence Say? London: King's Fund; 2010.

[14] Vedsted P, Olesen F. Are the serious problems in can-cer survival partly rooted in gatekeeper principles? Anecologic study. British Journal of General Practice 2011,http://dx.doi.org/10.3399/bjgp11X588484.

[15] Jagger C, Gillies C, Moscone F, Cambois E, Van Oyen H, NusselderW, Robine J-M, EHLEIS team. Inequalities in healthy life years in the 25 countries of the European Union in 2005: a cross-national meta-regression analysis. Lancet 2005;372:2124-31.

[16] Starfield B, Kinder K. Multimorbidity and its measurement. HealthPolicy 2011, http://dx.doi.org/10.1016/j.healthpol.2011.09.004.

[17] Van Baal PH, Engelfriet PM, Boshuizen HC, van de Kassteele J,Schellevis FG, Hoogenveen RT. Co-occurrence of diabetes, myocardialinfarction, stroke, and cancer: quantifying age patterns in the Dutchpopulation using health survey data. Population Health Metrics2011;9:51.

[18] Commission on Social Determinants of Health. Closing the Gap ina Generation: Health Equity through Action on the Social Determi-nants of Health. Geneva: WHO; 2008.

[19] Mackenbach JP, Stirbu I, Roskam A-JR, Schaap MM, Menvielle G,Leinsalu M, Kunst $A E$, For the European Union Working Group onSocioeconomic Inequalities in Health. Socioeconomic inequalities inhealth in 22 European countries. New England Journal of Medicine2008;358:2468-81.

[20] Van Doorslaer E, Masseria C, Koolman X. Inequalities in access tomedical care by income in developed countries. Canadian MedicalAssociation Journal 2006;174:177-83.

[21] Commission of the European Communities. Green Paper on the Euro-pean Workforce for Health. COM/2008/0725. Brussels: Commissionof the European Communities; 2008. 
Groenewegen, P.P., Dourgnon, P., Greß, S., Jurgutis, A., Willems, S. Strengthening weak primary care systems: steps towards stronger primary care in selected Western and Easte European countries. Health Policy: 2013, 113(1), 170-179

[22] Van den Heuvel A, Aarendonk D, Groenewegen PP, De Maeseneer J.The European Forum for Primary Care and the European Commissionconsultation on the European workforce for health: some emergingmessages. Quality in Primary Care 2009;17:307-9.

[23] Ros CC, Groenewegen PP, Delnoij DMJ. All rights reserved, or can wejust copy? Cost sharing arrangements and characteristics of healthcare systems. Health Policy 2000;52:113.

[24] Marrée JTC, Groenewegen PP. Back to Bismarck: Eastern EuropeanHealth Care Systems in Transition. Aldershot: Avebury; 1997.

[25] Boerma W, Van der Zee J, Fleming DM. Service profiles of gen-eral practitioners in Europe. British Journal of General Practice1997;47:481-6.

[26] Grielen SJ, Boerma WGW, Groenewegen PP. Unity or diversity? Taskprofiles of general practitioners in Central and Eastern Europe. Euro-pean Journal of Public Health 2000;10:249-54.

[27] Kringos DS. The Strength of Primary Care in Europe. Utrecht: NIVEL;2012.

[28] KBV. Struktur der Mitglieder in den Kassenärztlichen Vereinigun-gen zum 31.12.2010. Berlin: Kassenärztlichen Bundesvereinigung;2011.

[29] Kroneman MW, Van der Zee J, Groot W. Income development of gen-eral practitioners in eight European countries from 1975 to 2005.BMC Health Services Research 2009;9:26.

[30] Busse R, Riesberg A. Health Care Systems in Transition. Copenhagen,Germany: WHO Regional Office for Europe on behalf of the EuropeanObservatory on Health Systems and Policies; 2004.

[31] Schlette S, Lisac M, Blum K. Integrated primary care in Germany:the road ahead. International Journal of Integrated Care 2009;9.Article/311-620.

[32] Götz K, Laux G, Mergenthal K, Roehl I, Erler A, Miksch A, Beyer M. Eval-uation der Hausarztzentrierten Versorgung in Baden-Württemberg.Public Health Forum 2013;21(1), 25.e1-25.e3.

[33] Chevreul K, Durand-Zaleski I, Bahrami S, Hernández-Quevedo C,Mladovsky P. France: health system review. Health Systems in Tran-sition 2010;12(6):1-291.

[34] Dourgnon P, Naiditch $M$. The preferred doctor scheme: a politi-cal reading of a French experiment of gate-keeping. Health Policy2010;94:129-34.

[35] Le Fur P, Yilmaz E. Referral to specialist consultations in France in2006 and changes since the 2004 Health Insurance Reform. Questionsd'économie de la santé. Irdes n 134; August 2008.

[36] Gerkens S, Merkur S. Belgium Health system review. Health Systemsin Transition 2010;12(5):1-266.

[37] Annemans L, Closon J-P, Closon M-C, Heymans I, Lagasse R, Mendesda Costa E, Moureaux C, Roch I. Vergelijking van kost en kwaliteitvan twee financieringssystemen voor de eerstelijnszorg in België.KCE reports 85 A Federaal Kenniscentrum voor de Gezondheidszorg;2008.

[38] Meeus P, Van Aubel X. Performance of General Medicine in Belgium,A Check-Up. Health Services Research (HSR). Brussels: BelgianNational Institute for Health and Disease Insurance (NIHDI); 2012.D/2012/0401/13.

[39] RIZIV-INAMI. Medisch verbruik vanuit geografisch perspectief. Vari-aties in de uitgaven van de verzekering voor geneeskundigeverzorging in België-Gegevens 2009. Brussels: RIZIV-INAMI; 2012.

[40] Kornai J, Eggleston K. Choice and solidarity: the health sector in East-ern Europe and proposals for reform. International Journal of HealthCare Finance and Economics 2001;1:59-84.

[41] Håkansson A, Ovhed I, Jurgutis A, Kalda R, Ticmane G. Familymedicine in the Baltic countries. Scandinavian Journal of PrimaryCare 2008;26:67-9.

[42] Busse R. Health care systems in EU pre-accession countries and Euro-pean integration. Arbeit und Sozialpolitik 2002;(5-6):41-50.

[43] Koppel A, Meiesaar K, Valtonen H, Metsa A, Lember M. Evaluation ofprimary health care reform in Estonia. Social Science and Medicine2003;56:2461-6.

[44] Rechel B, McKee M. Health reform in Central and Eastern Europe andthe former Soviet Union. Lancet 2009;374:1186-95.

[45] Liseckiene I, Boerma WGW, Milasauskiene Z, Valius L, Misevicienel, Groenewegen PP. Primary care in a post-communist country 10years later: comparison of service profiles of 
Groenewegen, P.P., Dourgnon, P., Greß, S., Jurgutis, A., Willems, S. Strengthening weak primary care systems: steps towards stronger primary care in selected Western and Eastern European countries. Health Policy: 2013, 113(1), 170-179

Lithuanian primarycare physicians in 1994 and GPs in 2004. Health Policy 2007;83:10513.

[46] Kruk ME, Porignon D, Rockers PC, Van Lerberghe W. The contributionof primary care to health and health systems in low- and middle-income countries: a critical review of major primary care initiatives.Social Science and Medicine 2010;70:904-11.

[47] Pölluste K, Kalda R, Lember M. Evaluation of primary health carereform in Estonia from patients' perspective: acceptability and sat-isfaction. Croatian Medical Journal 2004;45(5):582-7.

[48] Koppel A, Kahur K, Habicht T, Saar P, Habicht J, van GinnekenE. Estonia health system review. Health Systems in Transition2008;10(1):1-230.

[49] Atun RA, Menabde N, Saluvere K, Jesse M, Habicht J. Introducing acomplex health innovation - primary health care reforms in Estonia(multimethods evaluation). Health Policy 2006;79:79-91.

[50] Ovhed I, Hakanson A, Meakin R, Fowler R, Jurgutis A, LemberM. Report from the universities of Lund Malmo, London, Oxford,Klaipeda and Tartu. The Baltic Forum 19942000: a primary healthcare research workshop. Scandinavian Journal of Primary Health Care2001;19(4):211-3.

[51] Jurgutis A, Vainiomäki P. Operational system of evidence basedand widely recognised quality indicators for PHC performance; pro-posal document for discussions with stakeholders. EU BSR ProgramImprim Project Report 2011.

[52] Liseckiene I, Miseviciene I, Dudonis M. Organizational changes in thecourse of the PHC reform in Lithuania from 1994 to 2010. HealthPolicy 2012;106:276-83.

[53] Jurgutis A, Vainiomäki P, Sta`sys R. Primary health care qualityindicators for a more sustainable health care system in Lithuania.Management Theory and Studies for Rural Business and Infrastruc-ture Development 2011;26(2).

[54]'Sumskas L, Valius L, Klumbien'e J, Raila G. Health promotion, dis-ease prevention and evaluation of vocational training, professionalcompetencies of family physicians in Lithuania (Lithuanian lang.).Lietuvos bendrosios praktikos gydytojas 2010, tomas XIV, Nr. 6.

[55] Peciura R, Jankauskiene D, Gurevicius R. The search for the criteriain reforming health care: evaluation of the spatial accessibility ofprimary healthcare service. Medicina (Kaunas) 2006;42(11).

[56] Jurgutis A, Martink 'enas A, Raudonyt'e J, Bumblys A. The comparisonof the primary health care institutions in accordance with the comor-bidity and the consumption of the secondary health care level service(Lith lang.). Health Sciences (Lithuanian) 2007;(N 4), 1144-1120.

[57] Pilot project carried out in Lithuania and Latvia.Jurgutis A, editor.Quality indicators for high quality PHC performance. EU BSR ProgramImprim project report 3. 2012.

[58] Boerma WGW, Pellny M, Wiegers TA, Kringos DS, Rusovich M. Eval-uation of the Organizational Model of Primary Care in Belarus. ASurvey-Based Project in the Regions of Minsk and Vitebsk. Copen-hagen: WHO; 2009.

[59] Richardson E, Boerma W, Malakhova I, Rusovich V, Fomenko A. Health care systems in transition: Belarus. European Observatory onHealth Systems and Policies 2008;10(6).

[60] Tumelevich N, Ovhed I, Stribolt W. Strengthening Primary HealthCare in Remote Areas. EU BSR Program Imprim project report 8; 2012.

[61] Or Z, Cases C, Lisac M, Vrangbaek K, Winblad U, Bevan G. Are HealthProblems Systemic? Politics of Access and Choice under Beveridgeand Bismarck Systems. Paris: Irdes; 2009 (working paper 27).

[62] Oleszczyk M, Svab I, Seifert B, Krzton-Krolewiecka A, Windak A. Fam-ily medicine in post-communist Europe needs a boost. Exploring theposition of family medicine in healthcare systems of Central andEastern Europe and Russia. BMC Family Practice 2012;13:15.

[63] Oikonomou N, Tountas Y. The Greek economic crisis: a primaryhealth care perspective. Lancet 2011;377:28-9.

[64] Hussey P, Anderson GF. A comparison of single- and multi-payerhealth insurance systems and options for reform. Health Policy2003;66:215-28.

[65] Saltman R, Busse R, Figueras J, editors. Social Health InsuranceSystems in Western Europe. Maidenhead: Open University Press;2004. 
Groenewegen, P.P., Dourgnon, P., Greß, S., Jurgutis, A., Willems, S. Strengthening weak primary care systems: steps towards stronger primary care in selected Western and Easter European countries. Health Policy: 2013, 113(1), 170-179

[66] Thompson S, Dixon A. Choices in health care: the Europeanexperience. Journal of Health Services Research and Policy2006;11:167-71.

[67] Groenewegen PP, Dixon J, Boerma WGW. The regulatory envi-ronment of general practice: an international perspective. In:Saltman RB, Busse R, Mossialos E, editors. Regulating EntrepreneurialBehaviour in European Health Care Systems. Buckingham: Open Uni-versity Press; 2002. p. 200-14.

[68] Greß S, Baan CA, Calnan M, Dedeu T, Groenewegen PP, HowsonH, Maroy L, Nolte E, Redaèlli M, Saarelma O, Schmacke N, Schu-macher K, Van Lente EJ, Vrijhoef B. Coordination and managementof chronic conditions in Europe: the role of primary care positionpaper of the European Forum for Primary Care. Quality in PrimaryCare 2009;17:75-86.

[69] Doran T, Campbell S, Fullwood C, Kontopantelis E, Roland M.Performance of small general practices under the UK's qual-ity and outcomes framework. British Journal of General Practice2010;60:335-44.

[70] Kroneman MW, Maarse H, van der Zee J. Direct access in pri-mary care and patient satisfaction: a European study. Health Policy2006;76:72-9.

[71] Van der Zee J, Kroneman MW. Bismarck or Beveridge: a beauty con-test between dinosaurs. BMC Health Services Research 2007;7:94.

[72] Grielen SJ, Boerma WGW, Groenewegen PP. Science in practice: canhealth care reform projects in Central and Eastern Europe be evalu-ated systematically? Health Policy 2000;53:73-89.

[73] Kringos DS, Boerma WGW, Bourgueil Y, et al. Primary Care 2010:Diagnosing Europe; 2013. In press.

[74] Groenewegen PP. Analyzing European health systems: Europeas a research laboratory. European Journal of Public Health2013;23:185-6. 
Groenewegen, P.P., Dourgnon, P., Greß, S., Jurgutis, A., Willems, S. Strengthening weak primary care systems: steps towards stronger primary care in selected Western and Easter European countries. Health Policy: 2013, 113(1), 170-179

\section{Box 1: Germany: GP models or 'Hausarztmod-} elle

Health care system: The German health care system is a social health insurance system with a strong distinction between ambulatory care and hospital care. Within ambulatory care GPs and medical specialists are directly accessible to patients. About $43 \%$ of all ambulatory care physicians are GPs [28]. The payment system of ambulatory physicians is a two-step process $[29,30]$. Step one is based on negotiations between the physician association (Kassenärztliche Vereinigung) and the sickness funds. The sickness funds pay an amount per insured person to the physician association. Step two is the allocation to individual physicians, partly based on fee for service and partly on a fixed amount for each patient who actually sees the doctor in a three-month period. The physician association includes GPs and ambulatory specialists.

Policy to strengthen primary care: Patients can choose their doctor every three months and that might be a GP or a specialist. In 2004 a co-payment of $€ 10$ at the first ambulatory visit in each three month period was introduced (except for vaccination and preventive services). It was primarily intended to reduce the number of physician visits. The co-payment also strengthened the position of GPs, since patients were obliged to pay additional co-payments for specialists if they have not been referred by their GP. This co-payment has been abolished in 2013, because the impact on the number of physician visits was negligible.

Moreover, a voluntary GP model was introduced in 2004 as well. Several legislative changes have resulted in an obligation for sickness funds to offer GP models for their insured. However, it is voluntary for the insured to enrol into a GP model. The GP model is based on contracts between individual sickness funds and associations of GPs (not the same associations as the physician associations that negotiate and divide the fees). In most cases the ambulatory specialists are not involved in the contract for the GP model.

GPs that enter a GP model have a patient list. Once patients enter the GP model they can only use specialist care (ambulatory or in hospital) after referral by their GP. Patients may switch GPs and from GP model to open model once a year (instead of every three months in the open system). In 2007 approximately one fifth of the publicly insured (who constitute $90 \%$ of the population) participated in a GP model. There is no up-to-date information about participation rates. Incentives: The incentive for patients to enter a GP model used to be a reduction of co-payments. In most cases patients got reimbursed for copayments in ambulatory care (max. $40 €$ per year). This incentive ceased to exist after the abolishment of the co-payments for physician visits. Moreover, some sickness funds refrained from reimbursing copayments as a matter of principle. They tried to convince their insured by offering service advantages, such as shorter waiting times for appointments. The incentive for GPs is that they receive additional reimbursement and a registration fee for each patient on their list. Financial incentives are negotiated in contracts between individual health insurers and GP associations. Since sickness funds are obliged to offer GP models, the bargaining process tends to favour the GP associations. As a consequence, financial incentives can be considerable.
Reimbursement for patients enrolled in GP models in some cases is increased by as much as $50 \%$. Sickness funds try to recover additional payments for GPs by requiring them to prescribe cost-effective pharmaceuticals.

Effects: There is little published evidence about the effects of GP models, but so far the effects on patient satisfaction and quality of care seem to be very small [31]. With very few exceptions [32], structure and processes of primary care have not been changed by GP models. Although patients need to receive a referral by a GP before visiting a specialist, this in most cases remains a formality and is not integrated into guidelines. Sickness funds are mostly unwilling or unable to sanction patients and GPs who do not follow their contractual obligations. 
Groenewegen, P.P., Dourgnon, P., Greß, S., Jurgutis, A., Willems, S. Strengthening weak primary care systems: steps towards stronger primary care in selected Western and Easter European countries. Health Policy: 2013, 113(1), 170-179

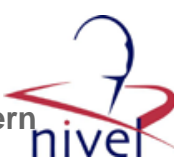

\section{Box 2: France: preferred doctor or 'médecin trai- tant'}

Health care system: The French health care system is a social health insurance system, as is Germany, but more centralized, with three main insurance schemes, one of which is the main national sickness fund (Caisse nationale d'assurance maladie des travailleurs salariés), and a stronger role of the government [33]. As in Germany, ambulatory care outside hospitals is provided both by GPs and specialists. Patients have direct access to specialists without referral.

Policy to strengthen primary care:The preferred doctor programme was introduced in 2006. It was preceded by the so-called referring doctor programme, introduced in 1998 as an optional scheme based on GP voluntary participation. However, this was never a success. Only one medical association (approximately $10 \%$ of GPs) and few patients (approximately $1 \%$ of the population) supported this. The GPs could ask their patients to sign a contract in which they bound themselves to this GP and were obliged to seek specialist care only after referral. One of the objections from the side of the GPs was that the scheme was excessively intrusive and curbed their autonomy, e.g. by introducing third party payment [34]. The preferred doctor scheme has been described as a weaker version of the referring doctor scheme [34]. Patients are invited to choose a doctor and be on the patient list of this doctor. The doctor can be either a GP or an ambulatory specialist. However, as it turned out, $99 \%$ of the preferred doctors are GPs. The preferred doctor was supposed to keep the personal medical records of enlisted patients. However, the electronic patient record, that was a core element of the reform, has never been implemented due to underestimated technical problems and overall inadequate financing of the project, but is still on the agenda, with an unclear time schedule. In the preferred doctor scheme, the patients bind themselves to a gate-keeping system. A number of specialties are excluded from the gate-keeping system and still directly accessible for patients under the preferred doctor scheme. These specialties are ophthalmology, gynaecology, stomatology (direct access is authorized for specific services, most of them related to prevention), psychiatry (for 16-25 years old patients) and paediatrics (the scheme does not include minors, who keep direct accessibility). In any case, it is the specialist who codes whether or not the patient accessed directly, when completing the form for the sickness fund reimbursement.

The preferred doctor scheme covered approximately $80 \%$ of the French population in 2007 . That is much more than the preceding scheme and might be related to the less restrictive character of the scheme. It has also been suggested that prior to the introduction of the reform, around $90 \%$ of the population had a family doctor that for a vast majority became their preferred doctor.

Incentives: The incentive for patients is higher reimbursement of the GP fees and higher co-payment if they visit a specialist without referral. The incentive for GPs is that they receive a capitation fee for follow up of patients on their list with certain chronic diseases. There was also a compensation for income loss for some specialties that were supposed to be most affected by the scheme through increase in fees or setting of new fees for specific acts that would be higher than the usual visit fee [34].

Effects: Overall little is known about effects of the scheme. More coordination in the care for the chronically ill might lead to better quality of care. The introduction of the preferred doctor scheme seems to have diminished the percentage of patients that consulted a specialist without referral [35], but at the same time slightly increased foregoing health care among those with no complementary insurance [34]. The scheme introduced more cost sharing for people without complementary insurance (more or less the working poor) and might thus have created small additional financial barriers in access to ambulatory care. Moreover, a discernible effect on overall health care costs is not expected as a result of other cost increasing influences. So although there might be an effect of the scheme, it is clearly not a landslide [33]. It is interesting though to note that some payments for performance were recently introduced for GPs. Also group practice is encouraged to tackle disparities in primary care supply and to stimulate cooperation between professionals. So the general picture is one of a step by step policy with no pure primary care target but rather focused on organizational development. 
Groenewegen, P.P., Dourgnon, P., Greß, S., Jurgutis, A., Willems, S. Strengthening weak primary care systems: steps towards stronger primary care in selected Western and Eastern European countries. Health Policy: 2013, 113(1), 170-179

\section{Box 3: Belgium: Centralized medical record (CMR) or 'globaal medisch dossier/dossier med- ical'}

Health care system: Belgium also has a social health insurance system. There are six associations of sickness funds. The National Institute for Health and Disability Insurance (RIZIV/INAMI) organizes reimbursement of the health care costs, prepares the health care budget and evaluates the evolution of health care costs. Medical specialists, both ambulatory and hospital-based, hospitals and GPs are directly accessible. The Belgian health interview survey showed that when they go to a GP, the majority of the population visits the same GP. Consequently, they might see themselves as having a fixed GP [36]. GPs and ambulatory specialists are paid fee for service. Patients pay on the spot the whole fee and go to their sickness funds to get reimbursement of the fee, minus the co-payment. A small minority of GPs are paid by capitation (covering about 165,000 out of $11,000,000$ Belgians in 2007) and this is on the increase [37].

Policy to strengthen primary care: The CMR for GPs was introduced in 1999. At first it was restricted to elderly patients (over 60 years of age) but later the age limit was gradually lowered and in 2002 it was extended to the whole population. Patients can choose a GP (or practice) to manage their medical file. The idea is that a complete medical file (which is very difficult when people visit GPs and specialists at will) will facilitate continuous care and coordination.

Incentives: The incentive for patients is a lower level of cost-sharing when they visit the GP who keeps their medical file and higher reimbursement for the first specialist consultation when referred by their GP. The incentive for GPs is a fixed amount per year $(€ 29,57$ in 2013) to be billed to the patients and fully reimbursed to them by the sickness funds [36]. In $200946 \%$ of the Belgian population had chosen to have a CMR, with higher participation rates among women $(50 \%)$, older people $(78 \%$ of the $75+)$, people with chronic conditions $(65 \%)$ and people living in the Flemish region $(58 \%)$ [38].

Effects: The CMR seems to be a positive factor in structuring primary care and the use of specialized care services. Having a CMR, and therefore a designated attending physician, for patients who have at least one contact per year with a physician (consultation or home visit), increases the total number of contacts (in 2008: 10.47 compared with 6.76), the number of contacts with the GP (in 2008: 7.42 compared with 4.66) and the percentage of patients who have one contact with a specialist ( $67 \%$ compared with $54 \%$ ). However, the frequency of contacts with a specialist is lower in patients with a CMR (in 2008: 4.29 compared with 4.86 ), as are the visits to emergency services (in 2008: 0.18 compared with 0.22) [38]. In the Flemish region where the CMR is used considerably more, the expenditure per patient for consultations with specialists is significantly lower $(7.3 \%$ below the mean for Belgium) then in the two other regions (respectively $5.8 \%$ and $25.6 \%$ higher in the Brussels region and the Walloon region than the mean for Belgium) [39]. Also, the number of patients indicating that they postponed healthcare for financial reasons is significantly lower in Flanders compared to the other regions $(10.9 \%$ versus $25.6 \%$ in the Brussels region and $13.9 \%$ in the Walloon region) [38]. 
Groenewegen, P.P., Dourgnon, P., Greß, S., Jurgutis, A., Willems, S. Strengthening weak primary care systems: steps towards stronger primary care in selected Western and Easter European countries. Health Policy: 2013, 113(1), 170-179

Box 4: Estonia: rapid introduction of family medicine based primary care

Health care system: During the Soviet period Estonia had a state-funded, centralized health care system (Semashko system), that was transformed into a mandatory social health insurance system with a single health insurance fund. [48]

Policy to strengthen primary care: From all post-soviet countries Estonia was most successful in implementing ambitious reform to strengthen primary care. It was the first CCEE to introduce family medicine based primary care for the whole population. All primary care providers became private, independent contractors and the population has freedom to list with the GP of their choice. Success of this complex innovation was enhanced by strong leadership, good coordination between policy and operational level, a careful changemanagement strategy to avoid direct confrontation with narrow specialists and an early investment in training to get a critical mass of primary health care professionals [49]. The other CCEE have chosen more gradual implementation of primary care reform.

The explicit policy of keeping new payment systems and contracts 'simple', which included gatekeeping, appears to be a critical success factor in securing cooperation from GPs [49]. High speed of the reform also avoided strong opposition from the polyclinic specialists, which played a role in other CCEE. At the moment primary health care reform became a hot issue for political debates, Estonia already had implemented substantial and irreversible changes. Success factors were also strong leadership in academic family medicine and the establishment of primary care research networks, which made scientific evaluation of the reform possible [50]. In Estonia funding of primary care is based on contracts between GPs (independent contractors since 1998) and the health insurance fund. Primary care is free of charge to insured persons. Home visits are an exception, and patients pay a fee to receive a home visit. GPs receive a monthly ageweighted (and twice yearly re-calculated) payment from the insurance fund for every registered patient. Incentives: The new payment system introduced in 1998 was intended to support the $\mathrm{GPs}^{\prime}$ gatekeeping role and ensure continuity of care. As an incentive to increase comprehensiveness of PHC services additional to age-adjusted capitation fee feefor service-payment was introduced for procedures agreed upon by the Estonian Health Insurance Fund and the Association of Family Doctors. The fee for service part amounted between 18 and $30 \%$ of overall payment. In 2005 Estonia has introduced a voluntary quality bonus system. The main goal is to promote the GPs' active involvement in disease prevention, to ensure more effective management of patients with chronic diseases, and to motivate GPs to provide a broad range of services to the insured.

Effects: Evaluation showed that primary care has become more relevant to the people and that satisfaction with the patient-doctor relationship and amenities has increased [47]. The number of GPs participating in the quality bonus system increased from $62 \%$ in 2006 to $90 \%$ in 2010 . The proportion of insured persons who received preventive and follow-up services increased by $36 \%$ during the period $2006-2009$ [51]. 
Groenewegen, P.P., Dourgnon, P., Greß, S., Jurgutis, A., Willems, S. Strengthening weak primary care systems: steps towards stronger primary care in selected Western and Easter European countries. Health Policy: 2013, 113(1), 170-179

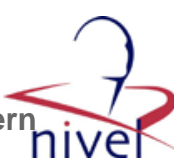

Box 5: Lithuania - ambitious reforms after independence, slowed down in the 2000s

Health care system: Like Estonia, Lithuania used to have a Semashko health care system during the Soviet period. It also introduced mandatory health insurance with a single insurance fund after independence.

Policy to strengthen primary care: Immediately after the restitution of independence there were nationally approved, ambitious strategies for reforms, aiming to strengthen primary health care and to introduce family medicine in the whole country. With support from European countries and Canada, academic family medicine has been developed very rapidly and the first GPs started after three years of residency in 1995. District internists and paediatricians had the opportunity to be retrained into GPs $[45,52]$. However, since 2000 the process of retraining slowed down and politically it was accepted to continue with district internists and paediatricians in primary care as an alternative to GPs. At the end of 2009 primary health care was provided by 1951 GPs ( $68 \%$ of primary care doctors), 479 district internists $(17 \%)$ and $447(15 \%)$ district paediatricians. To provide a wider range of medical services, district internists and paediatricians work in teams with 342 gynaecologists and 218 surgeons [53].

Primary health care is the entry point to the health care system. GPs are gatekeepers and patients need a referral to all specialists, except dermatologists. As in several other CCEE, patients have to pay for specialist care in case of self-referral. Since 1996 people have to be on the list of a primary care doctor and organization of their own choice. At the same time a new payment scheme was introduced: age-adjusted capitation. The introduction of private independent contractors started in 1999 and in 2008 half of primary health care institutions were private. Despite ambitious plans to introduce private independent contractors in the whole country, it has been politically accepted to keep the polyclinic model in the biggest cities. Even though there was a strong gatekeeping model, there were no incentives in the system to increase the comprehensiveness of services in primary care and to reduce referrals to secondary health care. Since 2006, as a consequence of decreased regulation of private primary care providers, mixed private practices came up. These are mini-polyclinics which provide primary health care (mainly capitation fee) and out-patient specialized services (fee for service).

Incentives: As a consequence of flat capitation without any incentives for preventive work and comprehensiveness of services, preventive activities of primary health care providers have decreased [54]. Lack of incentives also led to decreased accessibility of primary health care in remote areas, where patients practically have no or very limited choice of primary health care provider [55].

Effects: There is a large and increasing variation in referral rates between different primary health care providers, with the highest referral rates in former polyclinics and in the private clinics that provide primary and secondary health care $[56,57]$. Such models are accepted by the general population that in the past used to have direct access to secondary health care. Combined models (primary and secondary care working together) have also become quite common among private contractors. This has led to increased differences in quality and efficiency of primary health care services. The introduction of quality indicators and pay for performance in primary care has recently become an actual political issue for Lithuania. 
Groenewegen, P.P., Dourgnon, P., Greß, S., Jurgutis, A., Willems, S. Strengthening weak primary care systems: steps towards stronger primary care in selected Western and Easter European countries. Health Policy: 2013, 113(1), 170-179

Box 6: Belarus: gradual process - dual systems Health care system: The health care system of Belarus has largely stayed unchanged after independence. It is a hierarchical and centralized system with many features of the Semashko system of the Soviet period $[58,59]$.

Policy to strengthen primary care: Primary care in Belarus has been in transition since the late1990s as the country has experimented with different models of organizing services. The successful piloting of per capita resource allocation in Vitebsk region led to the nationwide introduction of new financing mechanisms for primary health care from 2000 and the implementation of per capita financing for services from 2004 In contrast to Estonia, Belarus has chosen gradual implementation of a model based on family medicine, following a decree of the Ministry of Health from 1998 on the gradual transition of the organization of primary care [58]. There is now a dual primary care system with GPs in rural areas and in the outskirts of some cities and the traditional polyclinic system in urban areas [59]. In remote rural areas primary care services are provided through feldsher-midwife posts staffed by mid-level medical professionals. A number of remote rural outpatient clinics have between ten and twenty beds that are mainly used for care of older people and people with chronic illnesses. Of the rural outpatient clinics, $70 \%$ are staffed by GPs (retrained district internists or paediatricians); the remainder still has separate doctors for adults and children. While the introduction of general practice in rural areas has demonstrated a success, there are no plans to extend into urban areas.

In urban polyclinics, the main categories of specialists are available for outpatient consultation. Patients can visit the relevant specialist without a referral from a primary care internist or paediatrician. The urban polyclinics also have diagnostic facilities: laboratory, $X$-ray, ultrasound and endoscopy. There are paralle networks of specialists and diagnostic facilities for adults and children which leads to duplication of diagnostic facilities at hospitals which also have both adult and paediatric specialists.

An important problem in primary care in Belarus has been the workload of primary care doctors, particularly as a result of the need to do a large number of routine annual check-ups, that in many cases have to be conducted by four to five narrow specialists (ENT specialist, neurologist, surgeon, ophthalmologist). These check-ups involve extensive paper work and cover large segments of the population (e.g. all school children twice a year, chronically ill patients, women of reproductive age). Primary care doctors also are responsible for carrying out annual fluorography screening for tuberculosis, opportunistic screening (particularly for cancers) and all sick leave authorizations. Primary health care physicians are salaried - consisting for $80-90 \%$ of a fixed amount, partly dependent on catchment population, and 10-20\% bonus for selected performance indicators.

Incentives: Making the work of primary care doctors more attractive and enabling a real shift in financing to the primary care sector and away from specialist and hospital care is a difficult challenge, as the lobbying capacity of the specialist sector is so well developed [59]. Salary levels of primary care physicians are 
Groenewegen, P.P., Dourgnon, P., Greß, S., Jurgutis, A., Willems, S. Strengthening weak primary care systems: steps towards stronger primary care in selected Western and Easter European countries. Health Policy: 2013, 113(1), 170-179

established centrally and depend on accumulated working time in the same practice, work in rural areas, and the size of the population served. Recently two regions, Gomel and Mogiliov, have introduced 27 new primary health care quality indicators to evaluate preventive work of primary care doctors and to measure use of more expensive levels of care, i.e. rate of ambulance visits in the district and hospitalizations for ambulatory care sensitive conditions. By meeting the indicators primary care doctors collect points, allowing to increase salary up to $50 \%$ above the centrally established level.

Effects: Pilot projects in the development of high quality primary health care have shown results in terms of increased patients' satisfaction, increased follow-up of disease and decreased workload at more expensive levels of care [60]. Recently the priority of national policy makers is to introduce measures to stimulate more appropriate use of specialized services. Therefore a national strategy for PHC development will be adopted and experiences from the pilots will be disseminated countrywide. 